then reviewed. Evolution on the basis of the statistics of DNA sequences is discussed, and Rowe explains the evolution of evolutionary stable strategies within the framework of game theory. The field of biological physics is vast, and this book barely touches a couple of corners.

The important issue here is not what physics theory has done for biology (which is not very much), but what it can do in the future, and to this end the book does a marvellous job of defining the arena. My own view is that biology is proving to be a goldmine for theoretical physicists at a time when large areas of traditional physics are almost exhausted. Read this book (and others) and get going!

Per Bak is at the Niels Bohr Institute, Blegdamsvej 17, 2100 Copenhagen, Denmark.

\section{Individual view}

\section{Metaphysics and the Origin of Species \\ by Michael T. Ghiselin \\ State University of New York Press: 1997. \\ Pp. 377. \$24.95, £19.50 (pbk).}

\section{Mark Ridley}

Michael T. Ghiselin is an idiosyncratic mix of biologist, historian and philosopher. In 1969 he published The Triumph of the Darwinian Method, which is still, after 30 years of the Darwin industry, the book I should recommend to a scientific reader who wanted to understand Darwin's thinking. In the early 1980s, assisted by a MacArthur prize, he was one of the biologists who rescued molecular phylogenetics from its 20-year obsession with humans and chimpanzees and redirected it to transform evolutionary biology. But he is probably best known for his campaign, beginning with a paper in 1966, to establish that biological species are, in a philosophical sense, individuals.

It sounds an odd claim, but only because of a pun. As Ghiselin says, "in the usual biological sense, 'individual' is a synonym for 'organism' but the ontological term is a much, much broader one." He does not mean that biological species are organisms (which clearly they are not), but that they are logically — he would say metaphysically — individuals as opposed to classes. Classes are spatiotemporally unrestricted and have defining properties by which you can recognize members, or instances, of the class; individuals are spatiotemporally restricted, noninstantiable (you do not point and say "now there is a particularly fine example of Bill Clinton") and lack defining properties.

For instance, there is a class of all chairs (defined in some suitable way, such as all four-legged furniture that humans use to sit on), and there are individual members of the class. A particular chair has its own history: it is built in a certain place, put in the library, has its arm broken by a student, is stained when a mug of coffee (existentially contrary to library rules) is spilled on it, and is finally destroyed by the gravity of a fat professor. Many scientific classifications do define classes: chemical elements are classes, for example gold consists of all elements with atomic weight 79 . But are biological species like the class of chairs, or the particular chair? Most biologists before Ghiselin accepted that each species is a class: thus we speak of a person as being a 'member' of Homo sapiens, and species as having 'definitions' drawn up by museum-bench taxonomists.

Ghiselin noticed that, because of evolution, biological species cannot have defining properties. All swans may be white now, but if one mutated to black it would not cease to be a member of the swan species (assuming it could interbreed as normal). A species originates in a speciation event, evolves indefinitely down a lineage, and becomes extinct, analogously to that individual chair. The attributes that a species happens to possess are a contingent matter, like the attributes the clothes or hairstyle - of a person. Individual attributes may help you to recognize someone at a certain time, but they do not logically define the person, because they can be changed without changing the person into someone else. Linnaean names, like Homo sapiens, are therefore proper names. A taxonomic description is logically a diagnosis not a definition.

In Metaphysics and the Origin of Species (the title deliberately alludes to the classics of Theodosius Dobzhansky and Ernst Mayr), Ghiselin makes his case fully, from first principles, and defends it against its many critics. In later chapters he explores the implications of the 'individuality thesis' in related topics, such as development and evolution, macroevolution and phylogenetics.

The book is of the kind that narrowminded laboratory scientists call philosophical and like to ignore. "Why bother to think, when you can do experiments!" (mutatis mutandis as biology matures into a descriptive science). There are no experiments in Ghiselin's book, and none of his questions can be answered experimentally. But many scientists and philosophers do like to think about these things. What will they find here?

Critics will find it personal to the point of egocentric ("The possibility that species are processes, rather than wholes composed of organisms, has perhaps never occurred to anyone besides me"), discursive to the point of rambling ("Be that as it may..." is a common paragraph opener), rabbinical about historical texts, and polemical to the point of rude. Supporters will find it stimulating and enjoy the insights across an exceptional range of subjects, they will admire the erudition ("Curiously, the original 'Strickland Code' of zoological nomenclature, to which Darwin
New in paperback

The Invisible World: Early Modern Philosophy and the Invention of the Microscope

\section{by Catherine Wilson}

Princeton University Press, $\$ 18.95, £ 14.95$

"Wilson shows that microscopic observations reinforced the contemporary idea of the living machine' - that is, a reductionist view of nature. And therein lies the ultimate paradox of our machine-driven science: the essence of our natural world remains hidden despite our increasingly sophisticated scientific technology", Willem Hackmann, Nature 380, 35 (1996).

\section{Subjected to Science: Human} Experimentation in America Before the Second World War

by Susan E. Lederer

Johns Hopkins University Press, \$15.95, £13

“The author's description of experimentation on children and animals before the Second World War is much more complete than her analysis of research on prisoners and members of the military.... Here analysis of the legal cases, however, leaves much to be desired", George J. Annas, Nature 374, 827 (1995).

\section{America's Pursuit of Precision} Bombing, 1910-1945

by Stephen L. McFarland

Smithsonian Institution Press, $\$ 19.95$

McFarland traces the evolution of bombsights and automatic pilots from early efforts to the dropping of atomic ordnance on Japan in 1945.

What Will Be: How the New World of Information Will Change Our Lives by Michael Dertouzos

HarperEdge, $\$ 14$

Speculations from the director of MIT's Laboratory for Computer Science.

\section{Deeper: A Two-Year Odyssey in Cyberspace}

by John Seabrook

Faber, $£ 6.99$

This literary internet travel book grew out of two articles written for The New Yorker magazine.

\section{Fantasia Mathematica} The Mathematical Magpie edited by Clifton Fadiman Copernicus, $\$ 19.95$ each

Two classic anthologies of mathematical stories, anecdotes, essays, rhymes, music, cartoons, aphorisms and other oddities, with authors ranging from Mark Twain and Lewis Carroll, to Aldous Huxley, George Gamow and H. G. Wells.

To the Arctic! The Story of Northern Exploration from Earliest Times

by Jeannette Mirsky

University of Chicago Press, \$16.95, £13.50 
was a signatory, actually refers to the names of taxa as proper names"), and be excited by the vigour of the prose from which Ghiselin's personality is inseparable. I waffled (in the oscillatory American sense) between the two. Either way, it is now the standard source for anyone who wants to find out what it means to call a species an individual.

Mark Ridley is in the Department of Zoology,

University of Oxford, Oxford OX1 3PS, UK.

\section{Novel adaptation}

\section{Enduring Love}

by Ian McEwan

Cape/Doubleday: 1997. Pp. 247. £15.99, \$23.95

\section{Marek Kohn}

If our minds contain modules adapted to detect cheating, as the evolutionary psychologist Leda Cosmides has proposed, we run the risk that these organs will reach uncomfortable conclusions about the individuals they have most opportunity to observe: ourselves. The people who are best at deluding others are those who are best at deluding themselves, reflects Joe Rose, the narrator of Enduring Love; they flourish, and so do their genes. But his powers of persuasion are not so well developed. His genes have not flourished either, because this is a Darwinian morality tale.

His commercial timing as a writer has been perfect, however. He has surfed every wave in the popular science tide: dinosaurs, black holes, quantum magic, superstrings, neuroscience, Darwin revisited.... But now it is too late for him to follow the career in scientific research that, according to the voice of his conscience, was his true calling. At one point he writes an article arguing that Victorian scientists were the last to enjoy the pleasure of narrative in their papers, and then realizes it does not stand up; it was not written in the pursuit of truth; it was not science but journalism. Ian McEwan also takes his science seriously, and for many years regretted doing English rather than a science degree.

Despite carrying too much guilt, too much bulk and too little hair, Joe enjoys the love of a beautiful young woman. He cannot quite believe his luck, but no neo-Darwinian mate-choice theorist would be surprised. And his partner Clarissa is unable to have children. The couple remain on a plateau of erotic arousal, enjoying endless proximal rewards without an ultimate goal, cheating the evolutionary system as well as the intellectual one.

Then, one day in the countryside outside London, Clarissa and Joe see a balloon in trouble. Joe is one of several men who throw themselves into the scene, assembling a fatally ad hoc male coalition. Any primatologist will tell you that if you were a boy about to be car-

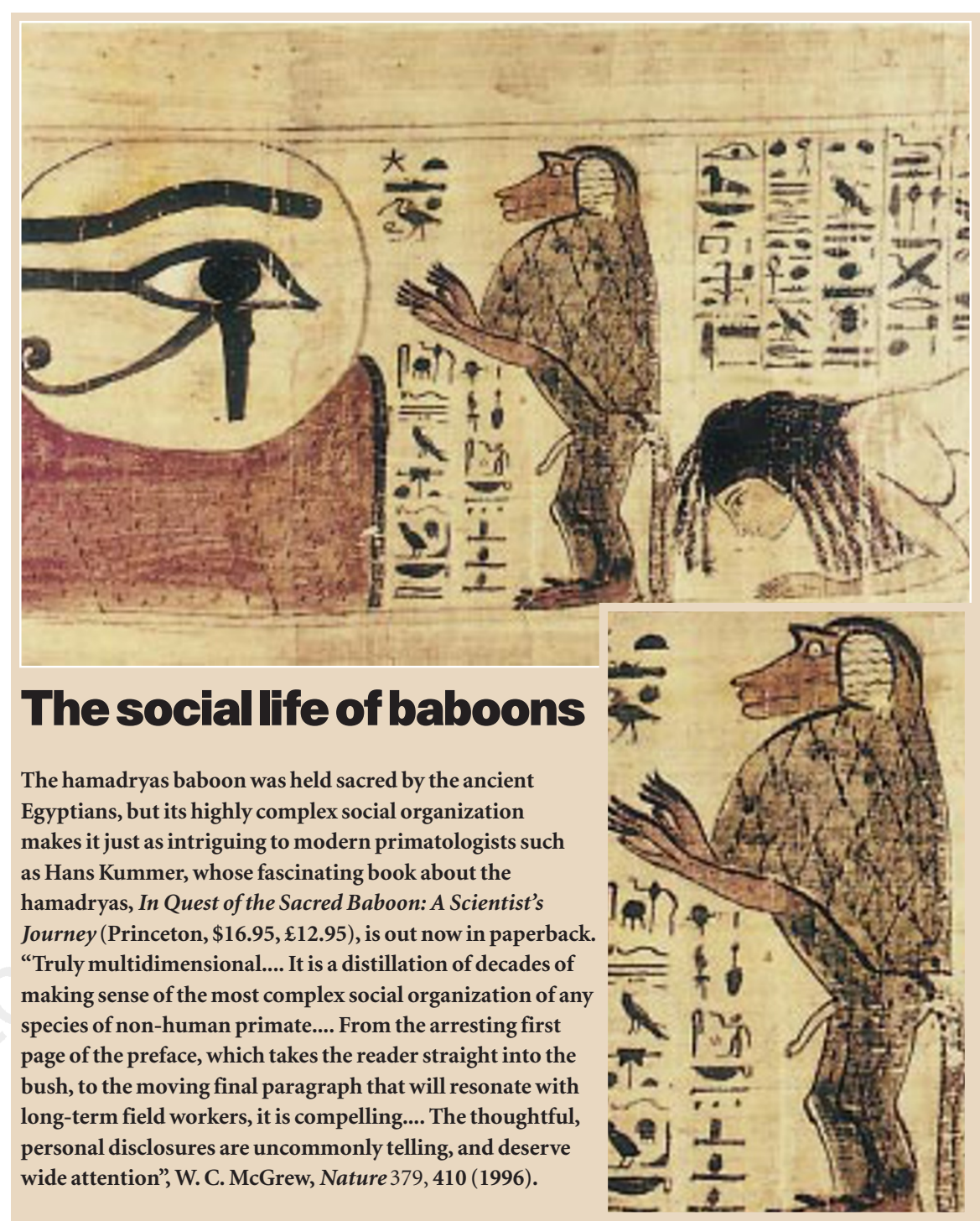

ried away in a balloon, you would be misguided to place your trust in a coalition of unrelated males who did not know each other. As the balloon rises, one man lets go. The balance of interests is upset: the value of cooperation collapses, and that of defection soars. Others then drop off, including Joe, but the last man hangs on. He is killed; the boy survives.

As well as the death, there is a second cataclysmic moment within this drama. One of the rescuers is a young man, Jed Parry, whose unconditional religious faith is suddenly joined by an equally absolute conviction that he and Joe are destined to be together in Christ. Joe diagnoses de Clérambault's syndrome, in which the subject believes the object of the obsession to be in love with him, however strong the evidence to the contrary. Jed's menacing ecstasy batters away at Joe's sanity, and pulls apart the bonds between Joe and Clarissa. On one side is the narrator's voice of reason; on the other are the Jesus freak's deranged faith and the Romantic inclinations of Clarissa, a student of Keats. Science finds both art and religion ranged against it.
As narrator, however, Joe has also been given the benefit of comprehensive emotional literacy, in reflection if not in dialogue. He fails to realize, for instance, that barren Clarissa might not care to hear his speculations about the adaptive value of a baby's smile. Joe is particularly taken with Ekman's recent work in the same field.

These scientific interpolations work better than the obvious oppositions between science and unreason. But the most effective science in Enduring Love is that which is not completely spelled out. The dynamics of the balloon coalition are one instance; another is the inexorable intrusion of reproductive interests, subtly evoked in Joe's encounters with the children of the dead man.

McEwan's final scientific flourish is an appendix, a cod scientific paper that recapitulates the story as a case history of de Clérambault's syndrome. Into this he drops a throwaway happy ending, thereby nailing the lid on Joe's vain thesis about science losing the plot.

Marek Kohn is at Flat 3, 27 Warrington Crescent, London W9 1ED, UK. Darwin's Expression of the Emotions and Paul 